\title{
'n Model vir fasette van strategiese beplanning vir inligtingstelsels in organisasies
}

\author{
P.J.S. Bruwer \\ Nagraadse Skool vir Bestuurswese, PU vir CHO, Potchefstroom 2520, Republiek van Suid-Afrika
}

Ontvang I Februarie 1990; aanvaar 20 April 1990

\begin{abstract}
The key to success for the information-system function in an organisation is an efficient planning system. According to Head $(1967,23)$ managers are classified in levels of strategic planning, management control and operational control. Managers on these levels are respectively responsible for long, medium and short term planning. The information-system function is compatable with other organizational functions. Like other organizational functions it also consists of managerial levels which has to plan for the effective and efficient utilization of scarce resources. In this research project data has been collected from top and middle managers of two large financial institutions in South Africa. Models were developed to assist management in their task of strategic long and medium term planning of the information-system function.

Die sleutel tot sukses vir die inligtingstelselfunksie in 'n organisasie is 'n effektiewe en doeltreffende beplanningstelsel. Volgens Head $(1967,23)$ se piramiedestruktuur van 'n inligtingstelsel word bestuurders geklassifiseer in vlakke van strategiese beplanning, bestuurbeheer en bedryfsbeheer. Bestuurders op hierdie vlakke is respektiewelik verantwoordelik vir lang-, medium- en korttermynbeplanning. Die inligtingstelselfunksie is soortgelyk aan ander organisatoriese funksies in die sin dat dit ook uit verskillende vlakke van bestuur bestaan, wat moet beplan vir die effektiewe en doeltreffende benutting van skaars bronne onder hul beheer in die uitvoering van hul taak. In hierdie navorsingsprojek is data vanaf die middel- en topbestuur van twee groot finansiële instellings in Suid-Afrika ingesamel en modelle ontwikkel wat middel- en topbestuur kan help in hulle taak van strategiese lang- en mediumtermynbeplanning van die inligtingstelselfunksie.
\end{abstract}

\section{Inleiding}

Die inligtingstelselbeplanningsproses vorm 'n integrale deel van die totale organisatoriese beplanning. Die inligtingstelselfunksie moet voortdurende tred hou met gedurig veranderende vereistes wat aan sy bronne gestel word. Net soos ' $n$ organisasie bronne an beplanning moet toedeel sodat dit in staat gestel kan word om aan te pas by die veranderinge van sy omgewing, so moet inligtingstelsels ook investeer in beplanningsbronne om te reageer op veranderinge in sy omgewing. Alhoewel die perspektiewe van die twee beplanningspogings kan verskil, is dit onteenseglik so dat die inligtingstelselbeplanning nou verband hou met die organisatoriese beplanningstelsel.

Volgens Anon. $(1985,7)$ sal die bruikbaarheid van inligting dramaties beperk wees sonder korrekte en behoorlik beplande ondersteuningstelsels. Gebrek aan stelselbeplanning kan onvermydelik lei tot ondoeltreffendheid en oneffektiwiteit. Dit kan hoofsaaklik aan die volgende faktore toegeskryf word:

- gebrek aan stelselintegrasie;

- swak aanpasbaarheid van stelsels;

- gebrek aan versoenbaarheid tussen inligtingstelsels en die organisasie;

- gebrek aan ondersteuning van die organisasie se doelwitte en strategies;

- ongeskikte of ontoereikende ondersteunings-tegnologie;

- gebrek aan gebruikersopleiding en orientasie te wyte aan swak implementeringsprosedures van stelsels; en

- ontoereikende ontwikkelde stelsels as gevolg van gebrek aan fondse wat veroorsaak is deur die gebrek aan of swak beplanning.

\section{Strategiese beplanning van Inligtingstelsels}

McLean en Soden $(1977,83)$ onderskei die volgende stappe betrokke by strategiese beplanning van inligtingstelsels:

1. Die daarstel van 'n missie van die bestuursinligtingstelsel (BIS)-organisasie.

2. 'n Diepgaande ondersoek van die organisasie om BISgeleenthede risiko's en bedreiginge te identifiseer.

3. Die daarstel van BIS-doelwitte wat die gewenste resultate wat bereik moet word, definieer en wat so nou moontlik verband hou met die organisatoriese strategiese doelwitte.

4. Die ontwikkeling van BIS-strategieë wat breë riglyne van aksie aandui en beskryf hoe voorafopgestelde doelwitte bereik moet word.

5. Die definiëring van BIS-beleid om as riglyn in die uitvoering van die strategie te gebruik. Spesiale aandag moet geskenk word aan die beleid aangaande die organisasie van die BIS, toekenning van skaars bronne en begrotings.

6. Die omskrywing van hierdie doelwitte, strategie en beleid in lang-, medium- en korttermynplanne.

7. Die implementering van die planne, meting van vordering en herhaling van die oefening oor tyd.

\section{Doel van die studie}

Die hoofdoel van hierdie studie was om 'n model te ontwikkel wat doeltreffend en effektief gebruik kon word vir stappe 2 en 3 hierbo genoem. Die model moes van so ' $n$ aard wees dat die mees kritiese faktore wat tot die sukses van die BIS bydra, geïdentifiseer en ook volgens prioriteite gerangskik kon word en verder gebruik kon word om die vordering van die inligtingstelselfunksie te monitor (dit wil sê stap 7 in die beplanningsproses).

\section{Die konseptuele model}

In die ontwikkeling van die model is navorsing gedoen 


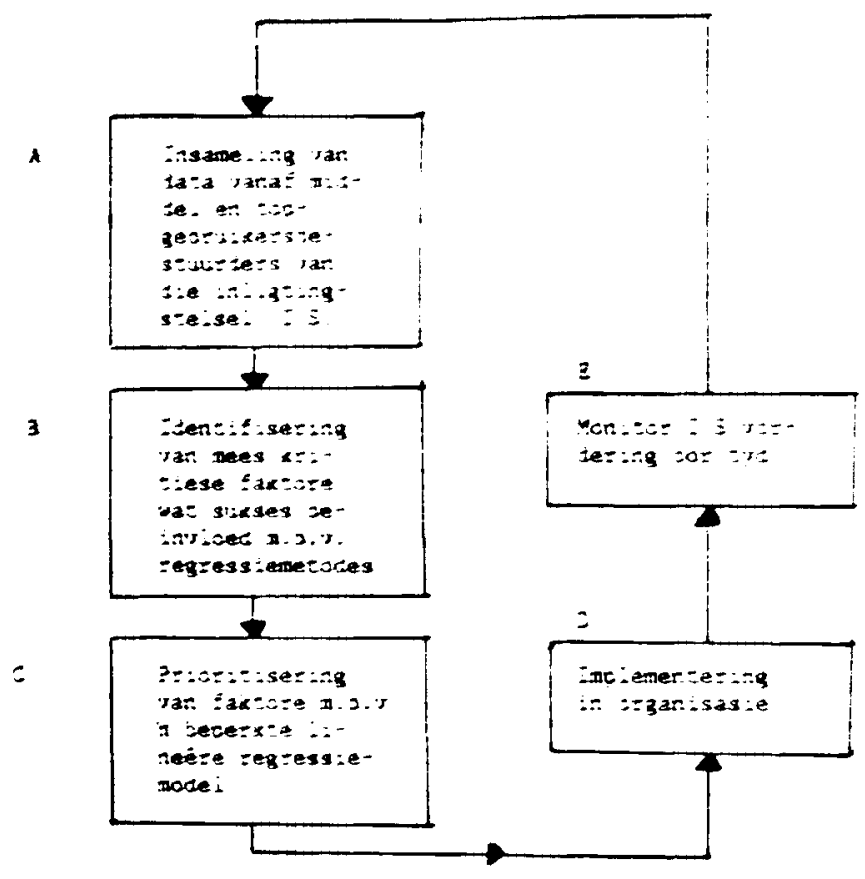

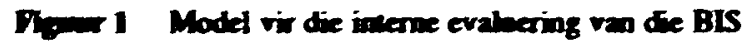

dew die owear (Brumer, 1983, Bruwer, 1984, Bruwer en Haxtingh, 1985), wert deur Alloway (1980) wat bebngrikheid en wertverrigtingsaspetse in die intigtingstebebkivwikik van 20 grool organisasies in die VSA bestudeer het, mavorsing deur Bailey en Pearson (1983), pogings van Pearson (1977), en Ives, Hamilion en Davies $(1980)$ om 'n kompake meetinstrument te ontwikkel vir die mating van effektiwiken van die inligaingstebel, studies deur Rockan (1982) en Martin (1982) met betretking lor kritiese suksesfaktore en wert deur Doyke en Millex (1984) gebruik.

In Figuw 1 word die model wat ontwitkel is, stematies angetoon.

\section{Insameling van data}

Deur gebruik te maak van die navorsing wat reeds gedoen is, is 'n vrelys ontwitkel waarin 34 faktore wat die sukses van die inligtingsteksel beinvloed, verval is. Die vraelys is in drie afdelings verdeel. In afdeling $A$ moes die bestuurders die belangrikheid van die 34 faksore op 'n 7-puntskaal evalueer. (Die 7-puntskaal is in die verlede met groot sukses in verskeie navorsingsprojekte getruik $(4,5,6,7))$. In afdeling $B$ is dieselfde aspekte gedek maar hier moes die bestuurders die werklike werkverrigting daarvan in die organisasie evalueer. Die laaste afdeling het vrae oor demografiese data bevat asook 'n vraag waar die totale sukses van die inligtingstelsel op 'n 7-puntskaal geëvalueer moes word.

Al die middel- en topbestuurders van twee groot finansietle instellings is genader om die evaluering te doen en 'n respons van gemiddeld $75 \%$ is terugontvang. $(\mathrm{N}=129$ in organisasie $A$ en $N=145$ vir organisasie $B$ ).

\section{Verwerking van data}

Tabel 1 bevat as voorbeeld 'n paar van die vrae wat in
Tabel 1 Aspette en akortings

\begin{tabular}{|c|c|c|}
\hline & Aspectre & Afrosing \\
\hline 1. & 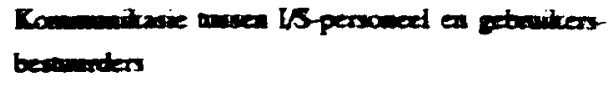 & The \\
\hline 2 & 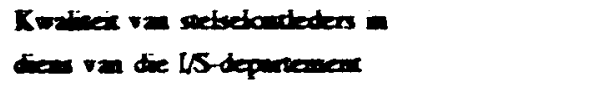 & $\mathrm{Kan}=$ \\
\hline 3. & 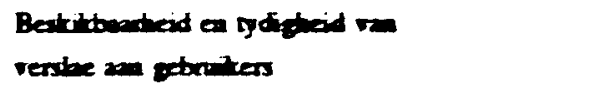 & Ty \\
\hline 4. & 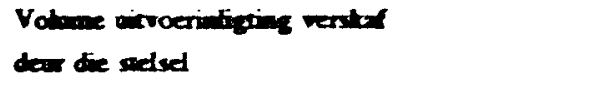 & Val \\
\hline 5. & 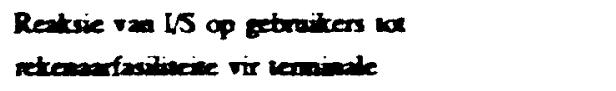 & Rets \\
\hline 6. & 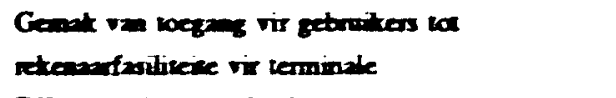 & Gent \\
\hline 7. & 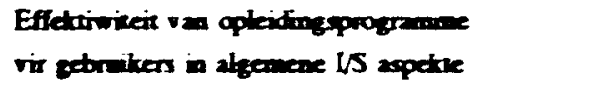 & ماapla \\
\hline $\mathbf{2}$ & Gebrizess se gerod van dectume & Deela \\
\hline 10 & 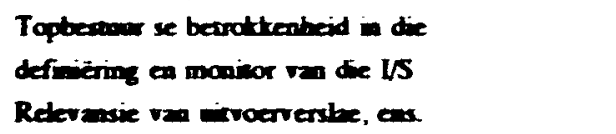 & $\begin{array}{l}\text { Top } \\
\text { Reter }\end{array}$ \\
\hline
\end{tabular}

Tabel 2 Suksesfaktore vir organisasie A

\begin{tabular}{|c|c|c|}
\hline 1. & $\mathbf{K} \mathbf{w n}^{2}$ & 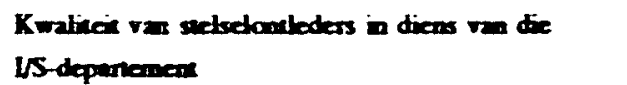 \\
\hline 2 & Vol & Volume van vivoerialigting verstaf deur die sebels \\
\hline 3. & Tydor & Tydsverloop vir die ondwitkeling van mure stedoets \\
\hline 4. & Afyd & 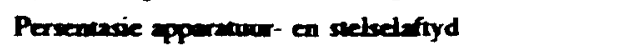 \\
\hline 5. & Aldow & Atkwentheid vas vitroctinliging \\
\hline 6. & Oniled & 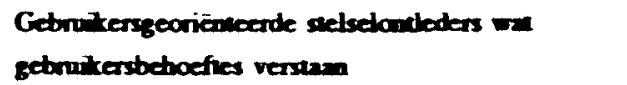 \\
\hline 7. & Setre & Denscturieit en -priventeid \\
\hline
\end{tabular}

die vraelys vervat is, sowel as die afkortings wat gebruik is.

\section{Regressiemetodes}

Ondat daar verkieslik gewerk wou word met so 'n cenvoudig moontlike model, is stapgewyse regressie gebruik met net cen vraag oor die lotale sukses van die inligtingstelsel (gemeet met in 7-puntskaal) as afhanklike veranderlike en die 34 aspekte waar die werkverrigting geevalueer moes word, as onafhanklike veranderlikes.

Die kriterium wat hier gebruik is, was die gedeelte van die cotale variansic van die afhanklike veranderlike as resultaat van 'n lineêre kombinasie van 'n gegewe versameling veranderlikes, ook bekend as die kwadreerde meervoudige korrelasiekoêfisiënt $\left(R^{2}\right)$. Omdat 'n aantal veranderlikes 'n verhoogde neiging van $\mathbf{R}^{2}$ to gevolg het, is die aangepaste $\mathbf{R}^{2}\left(\mathbf{R a}^{2}\right)$ wat hierdie verskynsel in ag neem, gebruik.

Alle moontlike deelversameling-meervoudige linêre regressie is ook gebruik in die ontleding van die data om die 'beste' deelversameling van die aspekte te vind, wat 
die variasie van suksesveranderlikes verklaar.

Vir organisasie A het sewe faktore altesaam $64 \%$ van die variansie van die afhanklike (afgekort as Sukses) verklaar, terwyl $75 \%$ van die variansie van die suksesveranderlike deur 10 faktore vir organisasie B verklaar is.

In Tabel 2 is die faktore wat betekenisvol is vir organisasie A vervat en in Tabel 3 dié wat betekenisvol is vir organisasie $B$.

Die volgende lineêre regressiemodel is gevind:

$\begin{aligned} \text { Sukses }= & 1,37+0,23 \text { (Kwalit) }+0,36(\text { Vol })+0,20 \text { (Tydsv) }-0,13 \\ & \text { (Aftyd) }+0,25 \text { (Akkur) }+0,20 \text { (Ontleed) }+0,14 \text { (Sekur) }\end{aligned}$

Vir organisasie $B$ is die volgende lineêre regressiemodel gevind:

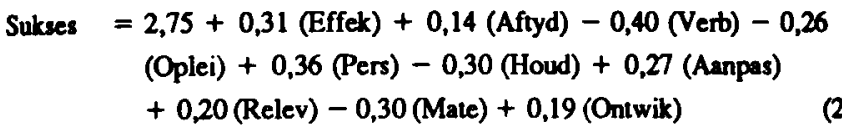

Prloritisering van die faktore met behulp van die beperkte lineêre regressiemodelmetode

Die agtergrond en filosofie van die beperkte lineêre regressiemodelmetode word volledig bespreek in Bruwer en Hattingh (1985). As voorbeeld word organisasie $B$ se data gebruik on die prioritiseringsprosedure te verduidelik.

Die doelfunksie in die beperkte lineêre regressiemodel is vergelyking (2). Vervolgens word een van die sogenaamde 'onafhanklike veranderlikes' as deel van die besprekingsvergelykings beperk tot die waardes 1,2 , $3, \ldots 7$. Vir elk van hierdie waardes word die doelfunksie geminimaliseer asook gemaksimaliseer. In totaal word 14 LP's dus opgelos. Vir organisasie B is die veranderlike Effek tot hierdie waardes beperk.

Die optimale oplossings word in Tabel 4 weergegee.

Daar is geen toelaatbare oplossing met Effek $=7$ nie. In Figuur 2 word hierdie oplossings grafies aangetoon.

Die volgende stap is om die verskil te vind tussen die 'maksimum optimale oplossing' van die veranderlikes (dit word bereik wanneer Effek beperk word tot 5 en die
Tabel 4 Optimale oplossings met effek beperk tot die waardes $1,2,3, . .7$

\begin{tabular}{|c|c|c|c|c|}
\hline \multirow[b]{2}{*}{ Vernderlike } & \multicolumn{2}{|c|}{ Effek $=1$} & \multicolumn{2}{|c|}{ Effek $=2$} \\
\hline & Min & Mats & Min & Maks \\
\hline Aftyd & 1.0 & 2.0 & 1.6 & 4.0 \\
\hline Verb & 20 & 3.0 & 26 & 3.0 \\
\hline Oplei & 2.0 & 2.0 & 24 & 2.5 \\
\hline Pers & 20 & 4.0 & 24 & 4.0 \\
\hline Houd & 4.0 & 6.0 & 4.2 & 5.5 \\
\hline Aarpass & 20 & 2.0 & 24 & 3.5 \\
\hline Relev & 20 & 5.0 & 24 & 5.0 \\
\hline Mate & 6.0 & 3.0 & 5.8 & 4.0 \\
\hline Ontwik & 20 & 3.0 & 26 & 4.0 \\
\hline \multirow[t]{2}{*}{ Sukses = } & 0.5 & 2.44 & 1.39 & 3.35 \\
\hline & \multicolumn{2}{|c|}{ Effek 3} & \multicolumn{2}{|c|}{ Effek 4} \\
\hline Veranderlike & Min & Maks & Min & Maks \\
\hline Aftyd & 2.2 & 6.0 & 28 & 5.0 \\
\hline Verb & 3.2 & 3.0 & 3.8 & 20 \\
\hline Oplei & 2.8 & 3.0 & 3.2 & 4.5 \\
\hline Pers & 2.8 & 4.0 & 3.2 & 4.0 \\
\hline Houd & 4.4 & 5.0 & 4.6 & 5.0 \\
\hline Aanpas & 2.8 & 5.0 & 3.2 & 5.0 \\
\hline Relev & 2.8 & 5.0 & 3.2 & 5.0 \\
\hline Mate & 5.6 & 5.0 & 5.4 & 4.5 \\
\hline Ontwik & 3.2 & 5.0 & 3.8 & 4.5 \\
\hline \multirow[t]{2}{*}{ Sukses = } & 1.88 & 4.25 & 2.37 & 4.50 \\
\hline & \multicolumn{2}{|c|}{ Effek 5} & \multicolumn{2}{|c|}{ Effek 6} \\
\hline Veranderlike & Min & Maks & $\operatorname{Min}$ & Maks \\
\hline Aftyd & 3.4 & 4.0 & 4.0 & 4.0 \\
\hline Verb & 4.4 & 1.0 & 5.0 & 5.0 \\
\hline Oplei & 3.6 & 6.0 & 4.0 & 4.0 \\
\hline Pers & 3.6 & 4.0 & 4.0 & 3.0 \\
\hline Houd & 4.8 & 5.0 & 5.0 & 4.0 \\
\hline Aanpas & 3.6 & 5.0 & 4.0 & 4.0 \\
\hline Relev & 3.6 & 5.0 & 4.0 & 5.0 \\
\hline Mate & 5.2 & 4.0 & 5.0 & 3.0 \\
\hline Ontwik & 4.4 & 4.0 & 5.0 & 5.0 \\
\hline Sukses $=$ & 286 & 4.75 & 3.35 & 4.09 \\
\hline
\end{tabular}

Tabel 3 Suksesfaktore vir organisasie B

\begin{tabular}{|c|c|c|}
\hline 1. & Effek & Effektiwiteit bedryf van bestaande stelsels \\
\hline 2. & Aftyd & Persentasie apparatuur- en stelselaftyd \\
\hline 3. & Verb & Verbetering van stelselontwikkelingstegnieke \\
\hline 4. & Oplei & Effektiwiteit van opleidirfgsprogramme vir gebruikers \\
\hline 5. & Pers & $\begin{array}{l}\text { Mate van persoonlike beheer wat die gebruiker het } \\
\text { oor I/S-dienste wat hy ontvang }\end{array}$ \\
\hline 6. & Houd & Houding van $\mathrm{I} / \mathrm{S}$-personeel teenoor gebruikers \\
\hline 7. & Aanpas & $\begin{array}{l}\text { Stelsel se aanpasbaarheid by veranderde } \\
\text { gebruikersbehoeftes. }\end{array}$ \\
\hline 8. & Relev & Relevansie van die uitvoerinligting \\
\hline 9. & Mate & $\begin{array}{l}\text { Mate van } \mathrm{I} / \mathrm{S} \text {-afdeling se insette by die ontwikkeling } \\
\text { van nuwe stelsels. }\end{array}$ \\
\hline 10. & Ontwik & $\begin{array}{l}\text { Mate wastoe inligtingsteisels ontwikkel word volgens } \\
\text { die spesifikasies van die gebruikers }\end{array}$ \\
\hline
\end{tabular}

Tabel 5 Verskille tussen werkverrigting en maksimum optimale oplossing

\begin{tabular}{lccc}
\hline Veranderlike & Werkverrigting & Optimale oplossing & Verskil \\
\hline Effek & 4.0 & 5.0 & 1.0 \\
Aftyd & 3.8 & 4.0 & 0.2 \\
Vert & 4.2 & 1.0 & -3.2 \\
Oplei & 3.7 & 6.0 & 2.3 \\
Pers & 3.9 & 4.0 & 0.1 \\
Houd & 4.5 & 5.0 & 0.5 \\
Aanpas & 3.9 & 5.0 & 1.1 \\
Relev & 4.5 & 5.0 & 0.5 \\
Mnte & 4.5 & 4.0 & -.5 \\
Ontwik & 4.2 & 4.0 & -.2 \\
\hline
\end{tabular}




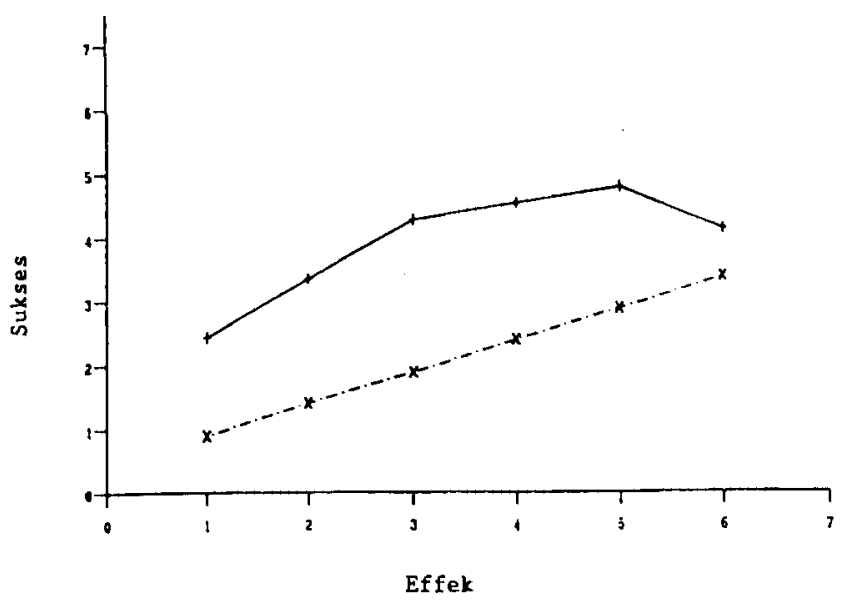

Fguur 2 Optimale oplossings met effek beperk tot die waardes $1,2 \ldots .7$

(dit word bereik wanneer Effek beperk word tot 5 en die vlak van die veranderlikes is soos wat dit tans die geval in organisasie B is.

In Tabel 5 is hierdie inligting vervat.

In Tabel 6 word die verskille soos verkry in Tabel 5 tesame met die verskille vir hierdie veranderlikes tussen hulle relatiewe belangrikheid en werklike werkverrigting aangedui. Die produk hiervan lewer 'n prioriteitsfaktor wat ook in Tabel 6 weergegee word.

Die prioriteitslys vir inligtingstelselaspekte wat die grootste invloed op die sukses van die inligtingstelsel het, is die volgende vir die organisasie B:

1. Effektiewe opleidingsprogramme vir gebruikers in algemene inligtingstelselvermoæ.

2. Effektiewe bedryf van bestaande stelsels.

3. Stelsels se aanpasbaarheid vir gedurige veranderende gebruikersbehoftes.

4. Houding van I/S-personeel teenoor gebruikers.

5. Relevansie van uitvoerverslae.

6. Persentasie apparatuur- en stelselaftyd.

7. Graad van persoonlike kontrole wat die gebruiker het aangaande die $\mathrm{I} / \mathrm{S}$-dienste wat hy ontvang.

Die ander drie aspekte met negatiewe prioriteitsfaktore hoef glad nie in hierdie stadium aandag te kry nie.

\section{Opsomming}

Die metode wat hier bespreek is, is reeds met groot vrug in 'n hele aantal groot organisasies toegepas om die mees kritiese leemtes in die $\mathbf{I} / \mathrm{S}$-mondering uit te wys en kan natuurlik jaarliks of tweejaarliks herhaal word om as monitor te dien. Die faktore wat in hierdie voorbeeld uitgewys is, is van kardinale belang vir die organisasie en kan as basis dien vir stappe 2 en 3 in die strategiese beplanningsproses.

\section{Verwysings}

Alloway, R.M. 1980. User manager's systems needs. CSIR working paper no. 56 (Sloan School of Management, MIT), May.
Tabel 6 Prioriteitsfaktore

\begin{tabular}{lccc}
\hline Veranderlike & $\begin{array}{c}\text { Verskil tussen op- } \\
\text { timale vlak en } \\
\text { werkverrigting }\end{array}$ & $\begin{array}{c}\text { Verskil wussen } \\
\text { belangrikheid en } \\
\text { werkverrigting }\end{array}$ & $\begin{array}{c}\text { Prioriteits- } \\
\text { fakior }\end{array}$ \\
\hline Effek & 1.0 & 2.2 & 2.2 \\
Aftyd & 0.2 & 2.3 & 0.46 \\
Verb & -3.2 & 1.5 & -4.80 \\
Oplei & 2.3 & 1.9 & 4.37 \\
Pers & 0.1 & 1.1 & 0.11 \\
Houd & 0.5 & 1.2 & 0.60 \\
Aanpas & 1.1 & 1.9 & 2.09 \\
Relev & 0.5 & 1.0 & 0.50 \\
Mate & -.5 & 0.4 & -.20 \\
Ontwik & -.2 & 1.6 & -.32 \\
\hline
\end{tabular}

Anon. 1985. Strategic planning for information systems. Infoplan news, April, p.7.

Bailey, J.E. \& Pearson S.W. 1983. A tool for computer user satisfaction. Management Science, Vol. 2 No. 5, 530-45, May.

Bruwer, P.J.S. 1983. Evaluating the performance of Computer-based information systems using a restricted linear regression model. Quaestiones Informaticae, Vol. 2, No. 3, 1-6. September.

Bruwer, P.J.S. 1984. A descriptive model of success for vomputer-based information systems. Information and Management, Vol. 7, No. 2, 63-67, April.

Bruwer, P.J.S. \& Hatting, J.M. 1985. Constrained regression models for optimization and forecasting. Orion, Vol. 1, No. 1, 2-15.

Dixon, W.J. \& Brown, M.B. 1981. Biomedical Compuler Programs, p-series. Berkeley, Los Angeles: University of California Press.

Doyle, B.A. \& Miller, J. 1984. Measuring the effectiveness of computer-based information systems in the financial services sector. Working paper no. 84-1. Cape Town: Graduate School of Business, University of Cape Town.

Head, R.V. 1967. Management information systems: a critical appraisal. Datamation, p.23, May.

IBM. 1984. Interactive chart uility users guide, 4th ed. Winchester, England, October.

Ives, B., Hamilton, B. \& Davis, G.B. 1980. A framework for research in computer based management information systems. Management Science, Vol. 26, No. 9.

Martin, E.W. 1982. Critical success factors of MIS/DP executives. MIS Quarterly, Vol. 6, No. 2, 28-39, June.

McLean, E.R. \& Soden, J.V. 1977. Strategic planning for MIS. New York: Wiley-Interscience.

Pearson, S.W. 1977. Measurement of compuler user satisfaction. Unpublished Ph.D. dissertation, Arizona State University.

Rockart, J.F. 1982. A survey of the banking sector. Unpublished technical report. Cape Town: Graduate School of Business, University of Cape Town, November.

SAS-institute inc. 1985. SAS users guide: basics, version 5th edition. North Carolina: Cary. 